\title{
Variability of cirrus clouds in a convective outflow during the Hibiscus campaign
}

\author{
F. Fierli ${ }^{1}$, G. Di Donfrancesco ${ }^{2}$, F. Cairo ${ }^{1}$, V. Marécal $^{3}$, M. Zampieri ${ }^{1}$, E. Orlandi ${ }^{1}$, and G. Durry ${ }^{4,5}$ \\ ${ }^{1}$ Istituto di Scienze dell' Atmosfera e del Clima, CNR, Italy \\ ${ }^{2}$ Ente Nazionale Energia e Ambiente, Dipartimento Clima, Italy \\ ${ }^{3}$ Laboratoire de Physique et Chimie de l'Environnement, CNRS and Université d'Orléans, France \\ ${ }^{4}$ Groupe de Spectroscopie Moléculaire et Atmosphérique, CNRS and Université de Reims, France \\ ${ }^{5}$ Service d'Aéronomie, CNRS and Institut Pierre et Simon Laplace, France
}

\begin{abstract}
Light-weight microlidar and water vapour measurements were taken on-board a stratospheric balloon during the HIBISCUS 2004 campaign, held in Bauru, Brazil $\left(49^{\circ} \mathrm{W}, 22^{\circ} \mathrm{S}\right)$. Cirrus clouds were observed throughout the flight between 12 and $15 \mathrm{~km}$ height with a high mesoscale variability in optical and microphysical properties. It was found that the cirrus clouds were composed of different layers characterized by marked differences in height, thickness and optical properties. Simultaneous water vapour observations show that the different layers are characterized by different values of the saturation with respect to ice. A mesoscale simulation and a trajectory analysis clearly revealed that the clouds had formed in the outflow of a large and persistent convective region and that the observed variability of the optical properties and of the cloud structure is likely linked to the different residence times of the convectively-processed air in the upper troposphere.
\end{abstract}

\section{Introduction}

Upper tropospheric ice clouds in the tropics (tropical cirrus) have a major effect on the terrestrial climate. Cirrus cover up to $20 \%$ of the whole Earth surface and up to $50 \%$ in the tropical region (Liou, 1986; Wang et al., 1996) and significantly impact on the Earth's radiative balance. They reduce the incoming solar radiation by reflection and absorb the upward infrared radiation emitted in the lower atmosphere.

The result may be a reduction in the net outgoing longwave radiation, causing a heating of the atmosphere (Hartmann, 1993). Such heating should be more efficient in the

Correspondence to: F. Fierli

(f.fierli@isac.cnr.it) stratosphere if the impact of the tropopause level tropical cirrus is included (Ackerman et al., 1988; Folkins and Martin, 2005). However, the effective impact of cirrus on the radiative balance depends also on several parameters such as underlying surface conditions, cloud height and thickness, and ice crystal size distribution.

Deep convection transports moist air from the ground to the upper troposphere and cirrus can form in hydrated air. In turn, the cirrus remove humidity through crystal formation and sedimentation thus influencing the water vapour budget in the tropical tropopause layer (TTL). Although it is well known that the air enters the stratosphere overworld after upwelling in the tropics (Holton et al., 1995), the mechanism of upward transport in the TTL is still uncertain. The main outflow of tropical deep convection is found around $13 \mathrm{~km}$ height $(350 \mathrm{~K}$ potential temperature). Although (Gettelman et al., 2002) showed that convective overshooting episodes are too rare to transport enough mass to supply the Brewer Dobson circulation, the water budget of the TTL is still currently under discussion.

Additional vertical transport in the TTL is provided by diabatic air mass lifting or descent induced by the radiative impact of cirrus. Nevertheless, a definitive picture of the dynamics related to radiation-cloud interaction is still unclear. Fueglistaler and Fu (2006), using Atmospheric Radiation Measurement (ARM) cloud measurements in the tropics, estimate that the increased short-wave radiation reflected by high altitude clouds is compensated by the reduced infrared radiation resulting in a cooling effect in the lower stratosphere. The modelling experiments by Corti et al. (2006) indicate that the cirrus cloud-radiation interaction can offer a pathway for upward mass transport in the tropical tropopause region. 
All these processes are dependent on the cloud persistence, the cloud spatial and vertical extension, and its particle size distribution. Therefore, it is important to characterize the microphysical properties of the upper tropospheric ice clouds, and to clarify the mechanisms leading to their formation. The processes involved in the formation and maintenance of tropical cirrus are not completely understood because few detailed measurements of their microphysical properties are available. The Center Equatorial Pacific Experiment (CEPEX) analysis (McFarquhar and Heymsfield, 1996) showed that the cirrus ice crystal dimension is related to the convective age and that particles with larger radar cross-sections are found nearer to the convective core. Pfister et al. (2001) identified two classes of cirrus from a comprehensive analysis of data from the Tropical Ozone Transport Experiment/Vortex Ozone Transport Measurement (TOTE/VOTE) experiment. The first class comes from particle and water vapour detrainment from convection. The second class of clouds is related to deep convection moistening but its formation is not directly linked to convective outflows. Once formed, the cirrus layers are maintained by dynamical or radiative processes. Massie et al. (2002) combined extinction data obtained by the Halogen Occultation Experiment (HALOE) and trajectories from the European Center for Medium-range Weather Forecasting (ECMWF). They found that half of the HALOE cirrus observations in the maritime continent originates from deep convection detrainment while the remaining part is likely to be formed by in-situ processes.

Microlidar optical observations of cirrus clouds were acquired on a stratospheric balloon on 24 February 2004 from 22:00 UTC (Short-duration Flight 4, SF4) in the framework of the 2004 HIBISCUS campaign (Pommereau et al., 2007). The HIBISCUS balloon experiment took place during the 2004 wet season in Bauru, Brazil $\left(49^{\circ} \mathrm{W}, 22^{\circ} \mathrm{S}\right)$. Bauru is located in a continental region where deep convection is very frequent (Liu and Zipser, 2005). The aim of the present paper is to identify convection as the formation mechanism of the tropical cirrus clouds observed by the ballonborne lidar and to correlate the differences in the cirrus microphysical characteristics with the variability of the convective processing of airmasses. A mesoscale meteorological model simulation and a trajectory analysis are used to link the observed clouds to previous convection activity, to estimate the convective age of the observed cirrus clouds (defined as the time elapsed between the convective uplift and the observation) and to correlate it with the observed optical properties.

Section 2 presents a description of the synoptic situation based on satellite measurements, the Microlidar observations and the comparison with simultaneous water vapour observations. Section 3 describes the mesoscale model simulations performed to estimate the convective age of the cirrus layers and its correlation with the observed properties. The main findings of the paper are outlined in the conclusions (Sect. 4).

\section{Observations}

\subsection{Satellite observations}

A persistent convective activity was recorded in central Brazil during the three days prior to the SF4 balloon flight. The South-America continental region was characterized by a positive precipitation anomaly during February 2004. In particular, from 20 to 24 February, the region of Bauru was under the influence of the South Atlantic Convergence Zone (SACZ). The SACZ gives rise to a large region of intense convection originating from the Amazon basin and extending south-eastward.

The first row in Fig. 1 reports the GOES-12 (Geostationary Operational Environment Satellite) infrared radiative temperature measurements from the $10.7 \mu \mathrm{m}$ channel every $12 \mathrm{~h}$ from 22 February at 15:00 UTC to 24 February at 15:00 UTC. The large scale convection structure and the wet air outflow associated to the SACZ can easily be seen. Convection develops during the days prior to the SF4 flight preferentially in the nighttime in a vast region north-east of Bauru. The convective systems are triggered at the location of a well marked frontal interface directed NW-SE which approximately extends from the center of the analyzed domain to its S-SE boundary. The convective activity has a clear diurnal cycle on 22 and 23 February. The GOES measurements from 14:45 UTC on 24 February show that convection develops earlier than on the previous two days.

Additional information on the cloud type and on the outflow structure comes from the observations of the Moderate Infrared Spectrometer (MODIS) onboard the TERRA and AQUA satellites. MODIS provides an estimate of Cloud Top Pressure (CTP) and optical thickness at nadir (for details see King et al., 1997). The closest overpasses were at 13:50 UTC on 24 February ( $11 \mathrm{~h}$ before SF4), at 16:30 UTC on 24 February ( $6 \mathrm{~h}$ before SF4) and at 02:50 UTC on 25 February ( $4 \mathrm{~h}$ after SF4). These observations are displayed in Fig. 2 where only clouds with top pressures above the $500 \mathrm{hPa}$ pressure level are plotted. From a comparison with groundbased radar observations, MODIS data show a positive bias in optical thickness and underestimate the cloud top height (Mace et al., 2005). Dessler and Yang (2003) discussed the cloud parameter uncertainties and estimated the thin tropical cirrus distribution based on optical thickness measurements from MODIS Terra $1.375 \mu \mathrm{m}$ channel. Since MODIS observations were not simultaneous with SF4, it is not possible to correlate them directly with the lidar observations to infer additional information on the observed clouds. Nevertheless the detection and the extension of optically thin clouds in the convective outflow complement the information obtained from the GOES data analysis. On 24 February (Fig. 2 top panels) a large convective region is located North of the balloon measurement site with several convective towers reaching a cloud top pressure lower than $150 \mathrm{hPa}$. The overall structure of the convective systems agrees well 

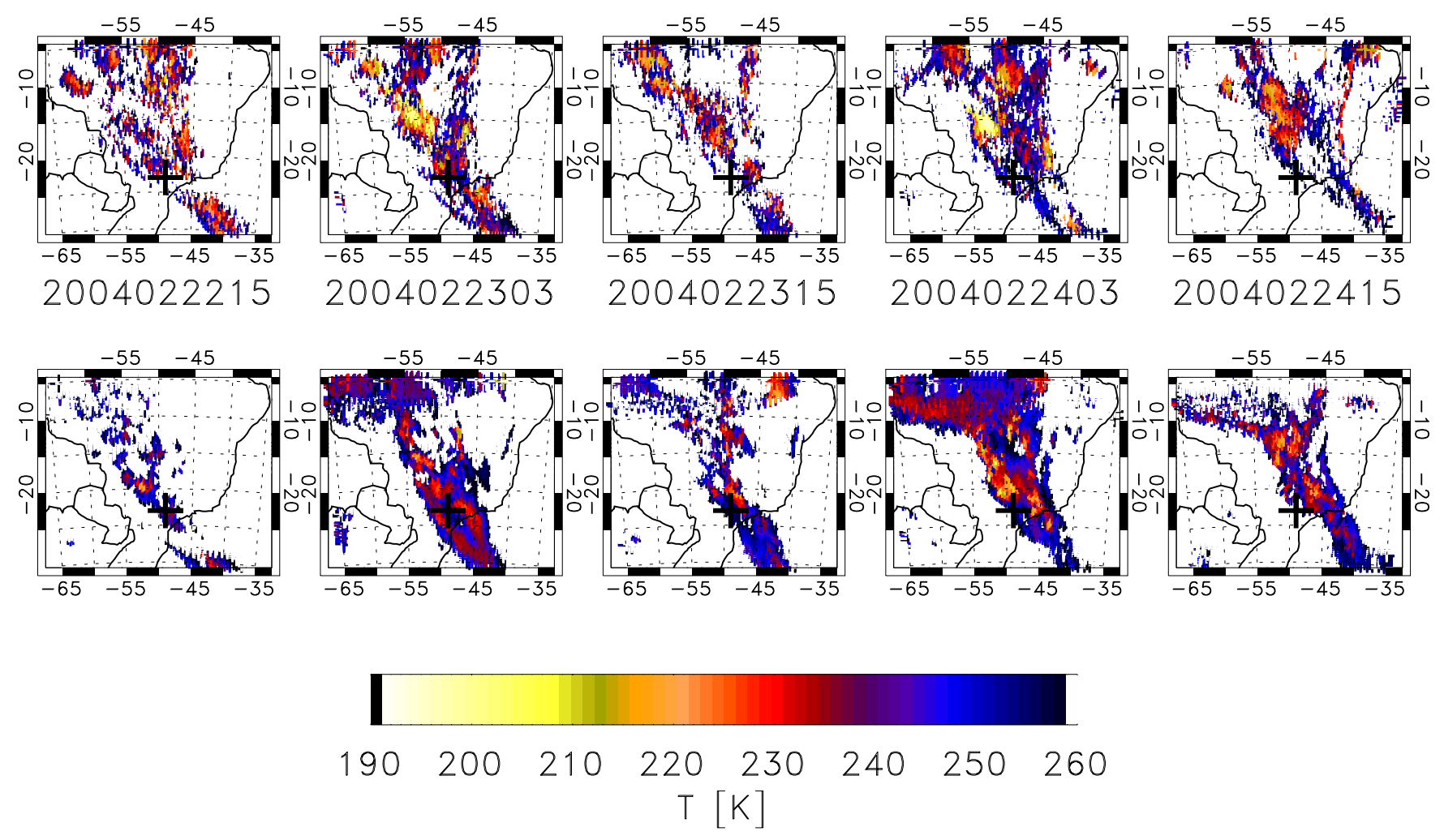

Fig. 1. Above: from left to right, infrared radiance temperature from GOES-12 10.7 $\mu$ m channel from 22 February 15:00 UTC, to 23 February 15:00 UTC. The position of SF4 flight is indicated with the black cross. Below: as above, but for infrared radiance temperature retrieved from BOLAM mesoscale model with RTTOV radiative transfer model.

with the GOES observations at 14:45 UTC (Fig. 1, top right panel). The optical thickness (Fig. 2, left panel) also shows that convective clouds are optically thick (up to 100) while the western part of the convective region $\left(55^{\circ} \mathrm{W}, 15^{\circ} \mathrm{S}\right.$ to $44^{\circ} \mathrm{W}, 28^{\circ} \mathrm{S}$ ) is characterized by a large and elongated cloud with optical thicknesses lower than 20 and top heights between 250 and $150 \mathrm{hPa}$. This is a signature of cirrus generated from the outflow of convective systems and transported south-eastward by the upper tropospheric jet located at the west side of the SACZ. Despite the partial spatial coverage, data at 16:30 UTC (middle panels) do not show the presence of high clouds in the SF4 measurement region (black box in Fig. 2). Data from the following day (Fig. 2, bottom panels) show the presence of large convective systems at $18^{\circ} \mathrm{S}$ latitude and smaller cloud systems east of Bauru. The SF4 region is characterized by optically thick clouds with variable heights. It is not possible to discriminate the presence of cirrus clouds since they could be masked by thicker clouds located at a lower altitude. The combination of GOES and MODIS images suggests that during the SF4 flight the upper troposphere was clearly perturbed by ubiquitous and persistent convection from which large cirrus clouds formed. Therefore it is likely that the region sampled by the microl- idar was influenced by both recent (up to 1 day) and aged (up to 3 days) convective outflows. Due to the MODIS time coverage, it cannot be demonstrated that cloud particles were present until the SF4 observation time. Additional details on the synoptic situation from TRMM (Tropical Rainfall Measurements Mission) for the 20-24 February period are given in Marécal et al. (2007).

\subsection{Balloon-borne Microlidar and Micro-SDLA hygrome- ter}

The lightweight microlidar made continuous observations during the SF4 flight starting at 23:00 UTC on 24 February 2004 and ending at 02:00 UTC on the following day. The microlidar observations shown in Fig. 3 were taken at the balloon floating altitude and during the first part of the descent, crossing the cirrus cloud between 00:00 UTC and 00:40 UTC on 25 February (corresponding to the abrupt stop in the measurements in Fig. 3). The microlidar acquires a vertical profile every $20 \mathrm{~s}$. The horizontal resolution is $2 \mathrm{~km}$ given a constant drift speed of the balloon and the vertical resolution is $15 \mathrm{~m}$. Details on the instrumental set-up are given in Di donfrancesco et al. (2006). 

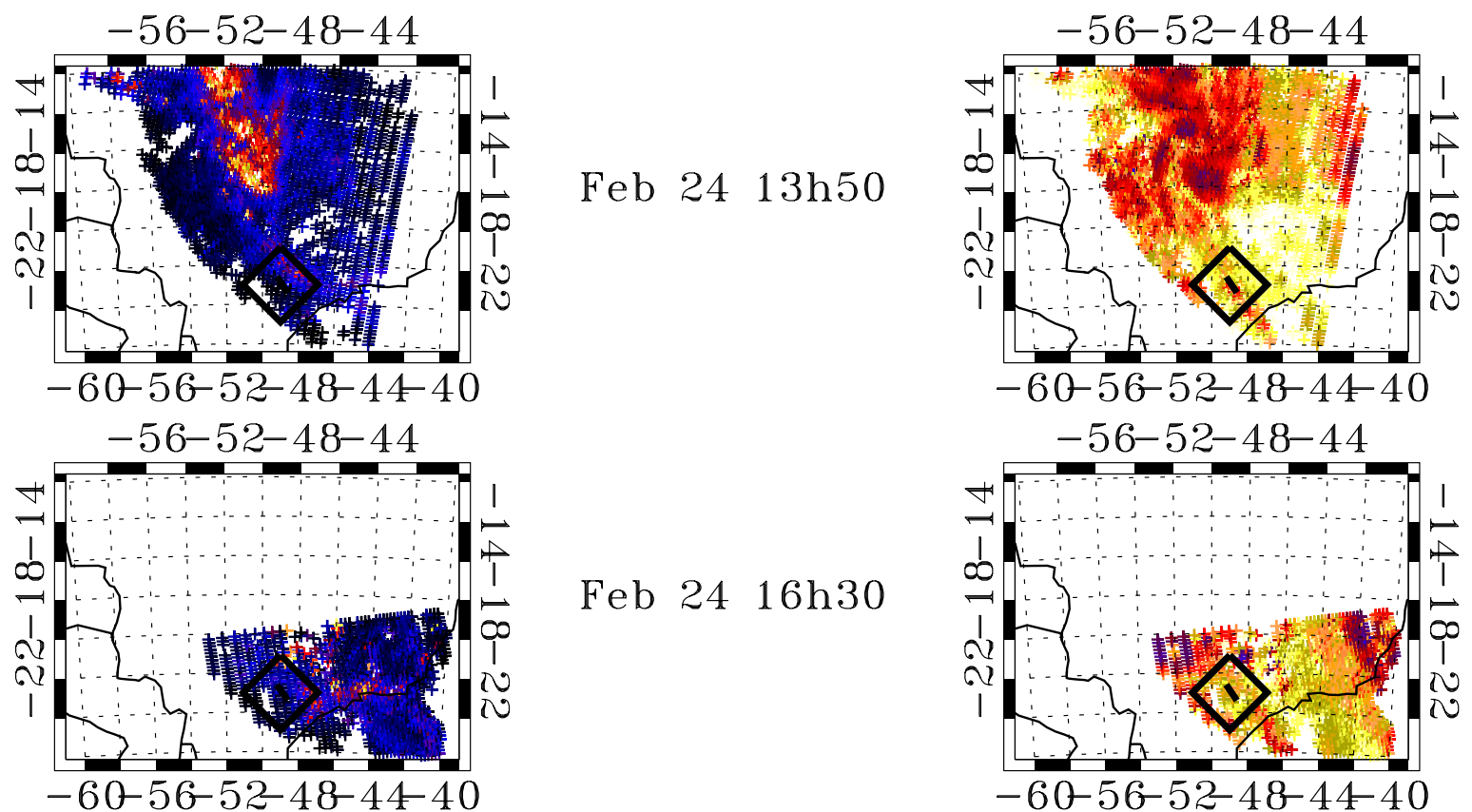

\section{Feb 24 13h50}

Feb 24 16h30
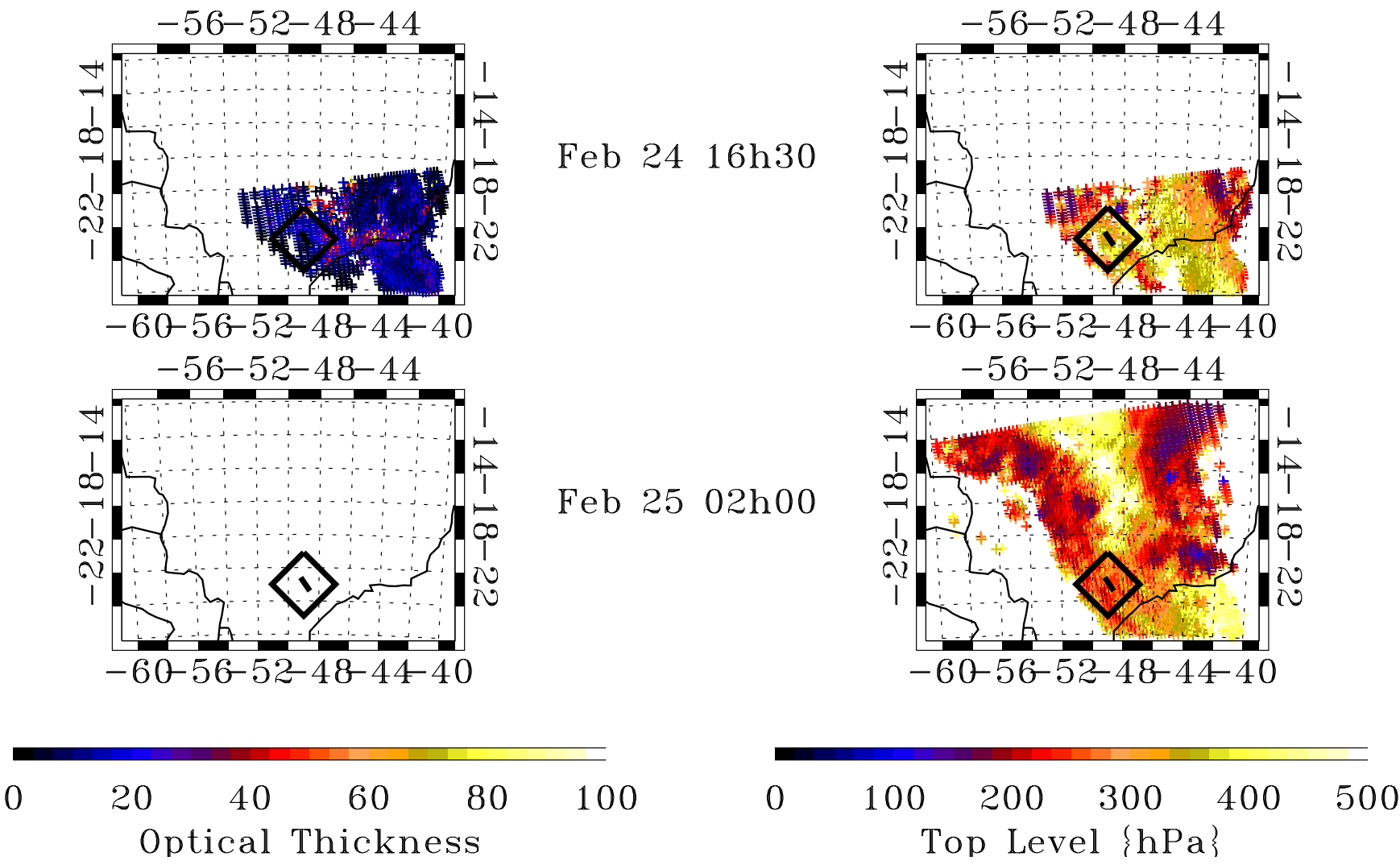

Fig. 2. Left: optical thickness estimated by MODIS imager onboard the TERRA satellite on 24 January 13:00 UT (above), on 24 January 16:30 UT (middle) and on 25 January 01:00 UT (below). The balloon position lies within the black box. Right: as left but for cloud top height.

The microlidar measures backscatter at parallel and perpendicular polarizations at $532 \mathrm{~nm}$ wavelength. The backscatter ratio is defined as the ratio between the total backscattered radiation and the molecular backscatter:

$\mathrm{BSR}=\frac{\beta_{m}+\beta_{a}}{\beta_{m}}$

$\beta_{m}$ is the molecular backscatter and $\beta_{a}$ is the aerosol backscatter. $\beta_{m}+\beta_{a}$ is proportional to the lidar signal while $\beta_{m}$ is calculated from density profile measured by the Bauru radiosounding. The aerosol backscattered light is split in a parallel $\left(\beta_{a}^{\|}\right)$polarization and a perpendicular $\left(\beta_{a}^{\perp}\right)$ polariza- tion. The aerosol depolarization is defined as the ratio between the two components:

$D=100 \frac{\beta_{a}^{\perp}}{\beta_{a}^{\|}}$

Typical values of $D$ in the presence of solid and aspherical particles range from $10 \%$ to $70 \%$ and the different values of $D$ are related to different scatterer dimensions and shapes. $D$ is thus used to identify the presence of particles in the ice phase, and, coupled with BSR, to classify the clouds in a qualitative way. The time evolution of BSR and $D$ vs. height from SF4 flight is plotted in Fig. 3 (upper panel for BSR 

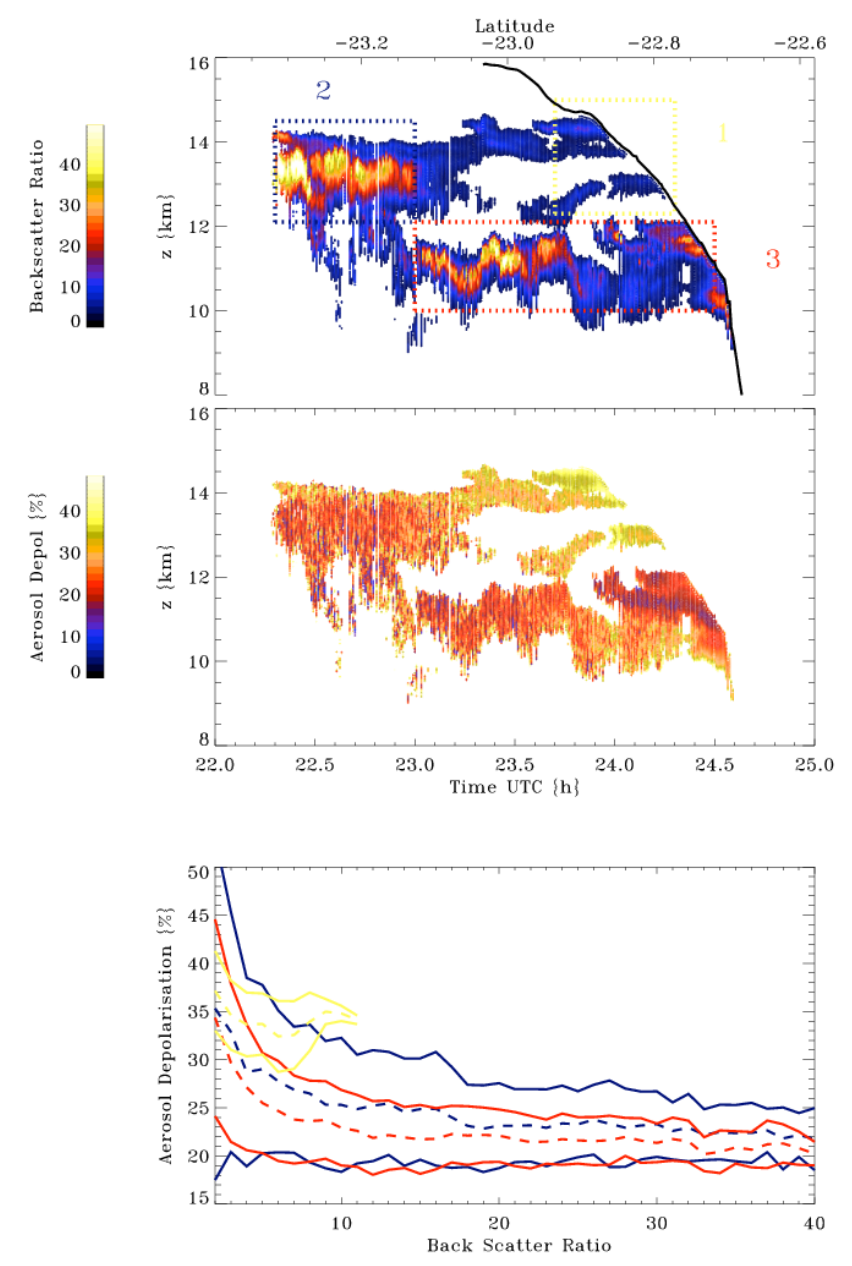

Fig. 3. Above: aerosol backscatter ratio at $532 \mathrm{~nm}$ (BSR) function of the flight time and height. The cirrus layers are enclosed in colored boxes as described in the text. Middle: same as above but for aerosol depolarization.Below: Aerosol backscatter ratio versus depolarization. Colors identify cirrus layers 1-3 (see text); dashed lines are the average $D$ values, and solid lines the standard deviation.

and lower panel for $D$ ). Three distinct layers can be identified: (1) a thin cirrus with low BSR $(<10)$ and high $D$ values $(D>30 \%)$ cirrus layers between 13 and $15 \mathrm{~km}$ height during the second part of the flight (in the orange box in Fig. 3, top panel), (2) a thick cirrus characterized by high BSR values (up to 45$)$ and low aerosol depolarization values $(D<30 \%)$ around $13 \mathrm{~km}$ height during the first half of the flight (blue box) and (3) a thick cirrus with similar BSR and $D$ values to layer (2) in the second part of the flight around $12 \mathrm{~km}$ height (red box). The different layers can be identified in Fig. 3 (lower panel) displaying the mean and the standard deviation of $D$ as a function of BSR. The colors correspond to the layers 1 to 3 in Fig. 3, top panel. Fig. 3 bottom panel shows that the optical properties of the layers 2 and 3 (blue and red lines)
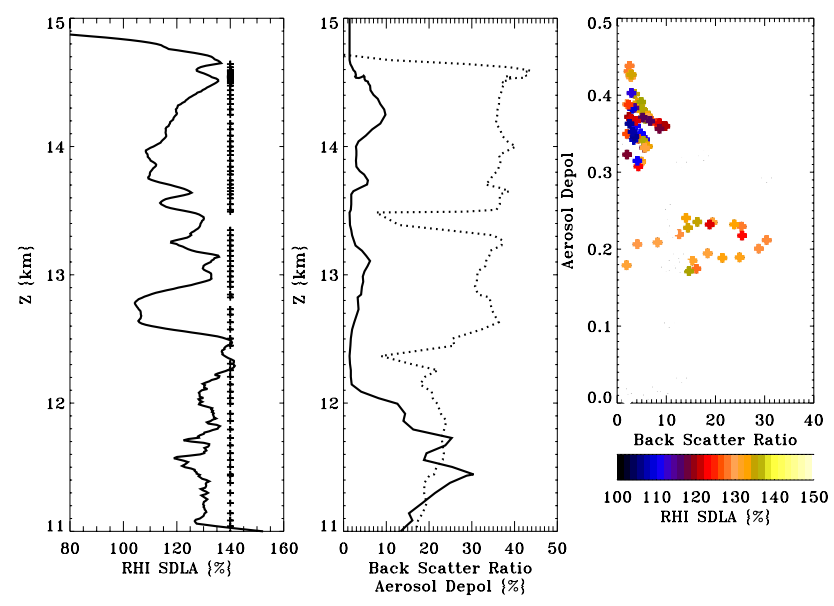

Fig. 4. Left: Ice Relative Humidity measured by Micro-SDLA. Crosses indicates the presence of solid particles (BSR $>1.4$ and $D>10 \%)$. Data are averaged on the lidar time resolution. Middle: BSR (solid line) and $D$ (dashed line). Right: Aerosol backscatter ratio versus depolarization. Colors identify RHI.

are similar with a large range of BSR values (1 to 60) and a quasi-constant value for $D$ for BSR values greater than 20 . Layer 1 (orange line) is characterized by BSR values ranging between 1 to 10 and higher values of $D$ than in layers 2 and 3 . The Micro-SDLA (balloon-borne diode laser spectrometer) hygrometer measured the water vapour in the gas phase on-board the SF4 simultaneously to the microlidar. The uncertainty of the Micro-SDLA water vapour measurements ranges from 5\% to 10\% (Durry et al., 2006). The Microlidar aerosol depolarization and the Micro-SDLA water vapour measurements are not fully coincident since the Microlidar data are screened for the layers nearest to the balloon leading to a $500 \mathrm{~m}$ distance in the horizontal. Nevertheless the optical parameters are sufficiently uniform on the horizontal scale to assume that the $500 \mathrm{~m}$ shift has a negligible impact on the comparison and we can consider that the Microlidar and Micro-SDLA sampled the same airmasses. Figure 4 displays the vertical profiles of the Microlidar backscatter ratio and depolarization together with the quasi-simultaneous water vapour profile measured by Micro-SDLA during the SF4 descent (25 February, 01:00 UT). For the comparison the Micro-SDLA water vapour data are averaged to match the Microlidar vertical resolution. The relative humidity with respect to ice (RHI) derived from Micro-SDLA measurements is also plotted in Fig. 4 and was calculated using the formula prescribed by the World Meteorological Organization for saturation pressure and the Marti and Mauersberger (1993) formula for saturation pressure over ice. The whole $11-15 \mathrm{~km}$ layer is supersaturated and RHI reach high values (135\% to $140 \%$ ) in three sub-layers. These sub-layers are located in cloud-free regions at $14.8 \mathrm{~km}, 13.4 \mathrm{~km}$ and at $12.4 \mathrm{~km}$ height while lower supersaturation values are measured inside the 
cirrus clouds. This indicates that the water content in gas phase is reduced inside the cirrus clouds due to its conversion into ice. In the cirrus layers the supersaturation is higher and more variable (ranging between 125\% and 130\%) in the lowest cirrus cloud. Therefore the ice nucleation and subsequent growth by water vapour diffusion seem to be more efficient or lasted longer in the cloud layer above $12.4 \mathrm{~km}$ height. The right panel in Fig. 4 displays RHI and $D$ as a function of BSR for the vertical profile. In the two distinct cirrus layers corresponding to the layers (3) and (1) identified in Fig. 3 different RHI values and optical properties are measured. Layer (3) is characterized by high BSR values and high values of supersaturation while layer (1) shows lower BSR values and lower values of supersaturation. This can interpreted as follows. Low BSR values reflect the presence of large ice particles that reduce the gas phase water content through efficient vapour deposition while higher BSR values can be associated to a larger number of smaller ice particles corresponding to a lower ice water content and a lower rate of water vapour deposition. On the basis of the satellite observations, it can also be assumed that the cloud particle variability is linked to the time when nucleation started in the outflows of the different convective systems developing during the days preeceding SF4 flight. A recent work from Shibata (2007), based on joint ground-based lidar and balloon-borne water vapour measurements, shows a similar behaviour with BSR and RHI peaks inside high altitude tropical cirrus. Shibata (2007) attempts to calculate the particle size from the estimated ice water content and suggests that high values of BSR are associated to small particles and a low ice water content. Several studies have tried to define a relationship between the lidar observed parameters (for instance $D$ ) and the scatterer microphysical properties. The modelling approach used in Liu and Mishchenko (2001) shows that the lidar depolarization values are related to the shape of the cloud particles but are not representative of the particle size in the micrometric range. Sassen and Benson (2001) demonstrate that the depolarization can be linked to the local temperature to infer the transition in cirrus ice crystal shape and the internal crystallographic features. Combining simultaneous lidar and in-situ observations Noel et al. (2004) propose a correlation between the depolarization and the particle shape. Whiteway et al. (2004) identify the crystal families forming in different locations with respect to the convective core, using the in-situ observations from the EMERALD campaign (Egrett Microphysics Experiment with RAdiation, Lidar, and Dynamics). Nevertheless the uncertainty remains too high to characterize quantitatively the microphysical processes occuring in convective outflows based solely on lidar observations. Therefore, the present work will focus on the correlation between the observed cirrus, the saturation variability at mesoscale and the macrophysical properties such as the cloud thermal history and the airmass convective age.

\section{Mesoscale modelling}

\subsection{Model description}

The convective transport properties for SF4 flight are analyzed with the BOLAM (BOlogna Limited Area Model) mesoscale model. BOLAM is a meteorological model based on the primitive equations in the hydrostatic approximation. The model variables are the horizontal wind components $\mathrm{u}$ and $v$, the potential temperature $\theta$, the specific humidity $q$ and the surface pressure $p_{s}$. The 3-D variables are defined in the vertical on hybrid coordinates and are distributed on a non-uniformly spaced Lorenz grid. The horizontal discretization is based on geographical coordinates with latitudinal rotation on an Arakawa C-grid. A Weighted Average Flux (WAF) scheme is used for the three-dimensional advection. The lateral boundary conditions are imposed by means of a relaxation scheme that minimizes the wave energy reflection (Davies, 1976; Lehman, 1993). Deep convection is parameterized with the scheme of Kain-Fritsch (Kain and Fritsch, 1990; Kain, 2004). The boundary layer scheme is based on the mixing length assumption and on the explicit prediction of turbulent kinetic energy (Zampieri et al., 2005). The surface turbulent fluxes are computed according to the Monin-Obukhov similarity theory. The parameterization of the effects of vegetation and soil processes (Pressman, 1994) is based on the water and energy balance in a four layer soil model. It includes the diagnostic computation of the skin temperature and of the humidity seasonally from the vegetation effects, the evapo-transpiration and the precipitation. The radiation is computed with a combined application of the scheme from Ritter and Geleyn (1992) and of the ECMWF operational scheme (Morcrette et al., 1998). Further details on the model are given in Buzzi and Foschini (2000). In order to analyse convection and transport processes influencing the region where SF4 flight was performed, the simulation starts $72 \mathrm{~h}$ before the observations (at 00:00 UTC on 22 February). The model has 60 vertical hybrid levels extending from the ground level to the top of the atmosphere defined at $0.1 \mathrm{hPa}$ with denser levels near the ground. This leads to a vertical resolution of $500 \mathrm{~m}$ in the upper troposphere. The horizontal domain has $240 \times 140$ grid points with a $20 \mathrm{~km}$ horizontal resolution. BOLAM uses the microphysical scheme from Schultz (1995) that treats five categories of condensate: liquid cloud, pristine ice (cloud ice), rain, snow and graupel. The amount of pristine ice and the crystal growth by water vapour diffusion are both dependent on the supersaturation level and are parameterized via the average mass of a single nucleated pristine crystal and a conversion rate control parameter. Ice removal is done through ice sedimentation, conversion to graupel, melting and evaporation. More details on the microphysical parameterization can be found in Schultz (1995). 


\subsection{Comparison with GOES data}

The analysis of the convective outflow transport requires accurate simulations of the life cycle, location and height of the convective clouds. To evaluate the accuracy of the BOLAM simulation a comparison is done between the GOES12 data and the cloud radiance temperature at $10.8 \mu \mathrm{m}$ estimated from the model thermodynamical and cloud variables with the RTTOV8.5 radiative forward model (Saunders and Brunel, 2004).

The simulated cloud radiance temperature fields simultaneous to the satellite observations are shown in the bottom row in Fig. 1. The model convective activity is in good agreement with the GOES-12 observations. The BOLAM model reproduces well the large scale dynamics and the location of the convergence region where most of the convection occurs. It is also worth noting that the comparison is still good at the scale of individual convective systems. This is illustrated by the BOLAM outputs that reproduce the high clouds observed on the western side of the convergence zone on 23 February at 03:00 UTC, 24 February at 03:00 UTC and 15:00 UTC. Figure 5 displays the high cloud fraction as seen by GOES and by BOLAM in the geographical domain of Fig. 1. A threshold of $240 \mathrm{~K}$ for the radiance temperature maximum is used to select the high clouds. The BOLAM model reproduces remarkably well the cloud cycle seen by GOES with a maximun of cloudiness at nighttime. It also underestimates the area covered by high clouds during the first part of the simulation while values quantitatively similar with the GOES data are obtained for the last $30 \mathrm{~h}$ of the simulation.

There is a general agreement between the BOLAM model and the GOES observations on the location and the lifetime of the main convective systems. This ensures that the dynamics of the convection and the large scale flows simulated by the model are realistic except in areas where the BOLAM model exhibits a positive bias the in cloud top temperature leading to an underestimation of the convective outflow height.

\subsection{Water vapour}

Figure 6, left panel, shows the BOLAM ice water content at $12 \mathrm{~km}$ height at 00:00 UTC on 25 February. Areas with enhanced ice water concentration $(>0.05 \mathrm{~g} / \mathrm{kg})$ indicate the presence of active convection. The comparison with the MODIS cloud top heights in Fig. 2 at 02:00 UTC gives a good agreement in the overall position of the two main cloud systems. The SF4 region (western yellow box) is located on the border of the outflow simulated by the model while it appears to be closer to the outflow core in the MODIS observations (Fig. 2 bottom right panel). Moreover MODIS shows that the SF4 region at 02:00 UTC is characterized by a variability of the cloud top pressure indicating the vicinity of the convective outflow. Since it is a nighttime measurement, it is not possible to couple this information with

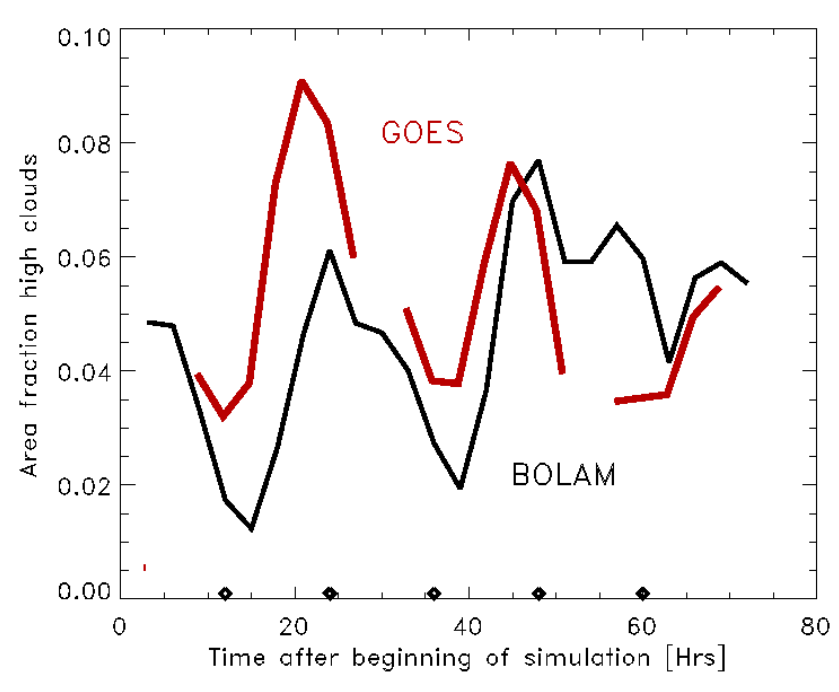

Fig. 5. High cloud area fraction from GOES observations (red line) and BOLAM simulations (black line). The time of the images of Fig. 1 are reported on the $\mathrm{x}$-axis as diamonds.

the optical thickness. The comparison with GOES observations at 15:00 UTC on 24 February (Fig. 1 right panels) shows, similarly as the comparison with MODIS data, that the main convective region simulated by BOLAM is slightly shifted eastward with respect to the observations. In order to compare the model with the SF4 observations that sampled layers that are potentially influenced by the variability of the outflow, the BOLAM vertical profiles were averaged in boxes chosen at several longitudes to account for the possible model shift in the location of the outflow. The horizontal size for the boxes is $1^{\circ}$ latitude by $1^{\circ}$ longitude. They are centered at $\left(49.5^{\circ} \mathrm{W}, 23^{\circ} \mathrm{S}\right),\left(48.5^{\circ} \mathrm{W}, 23^{\circ} \mathrm{S}\right)$ and $\left(47.5^{\circ} \mathrm{W}\right.$, $23^{\circ} \mathrm{S}$ ) and are indicated as yellow boxes in Fig. 6 left panel. The SF4 descent is located around the center of the western box. The RHI profiles derived from BOLAM (middle panel) show that the depth of the saturated layer increases with decreasing longitude while the supersaturation in this layer slightly decreases. Similarly to RHI, the ice water content (right panel in Fig. 6) shows a longitudinal variation. The BOLAM model predicts the peak in ice water content in the supersaturated layer at a lower altitude for the eastern box (around $11 \mathrm{~km}$ ). The Microlidar observations exhibit an ice layer in the $12.5-14.8 \mathrm{~km}$ range which is in closer (qualitative) agreement with the western part of the outflow and an ice layer in the $10.5-12 \mathrm{~km}$ altitude range which is in closer agreement with the eastern part of the outflow. The MicroSDLA data interpolated at the BOLAM vertical resolution indicate that the modelled RHI at $49.5^{\circ} \mathrm{W}$ is in good agreement with the observations in the highest cirrus layer while $\mathrm{RHI}$ at $48.5^{\circ} \mathrm{W}$ and $47.5^{\circ} \mathrm{W}$ agrees with the $10.5-12 \mathrm{~km}$ cirrus layer but underestimates the supersaturation. It should be mentioned that the horizontally averaged BOLAM RHI 

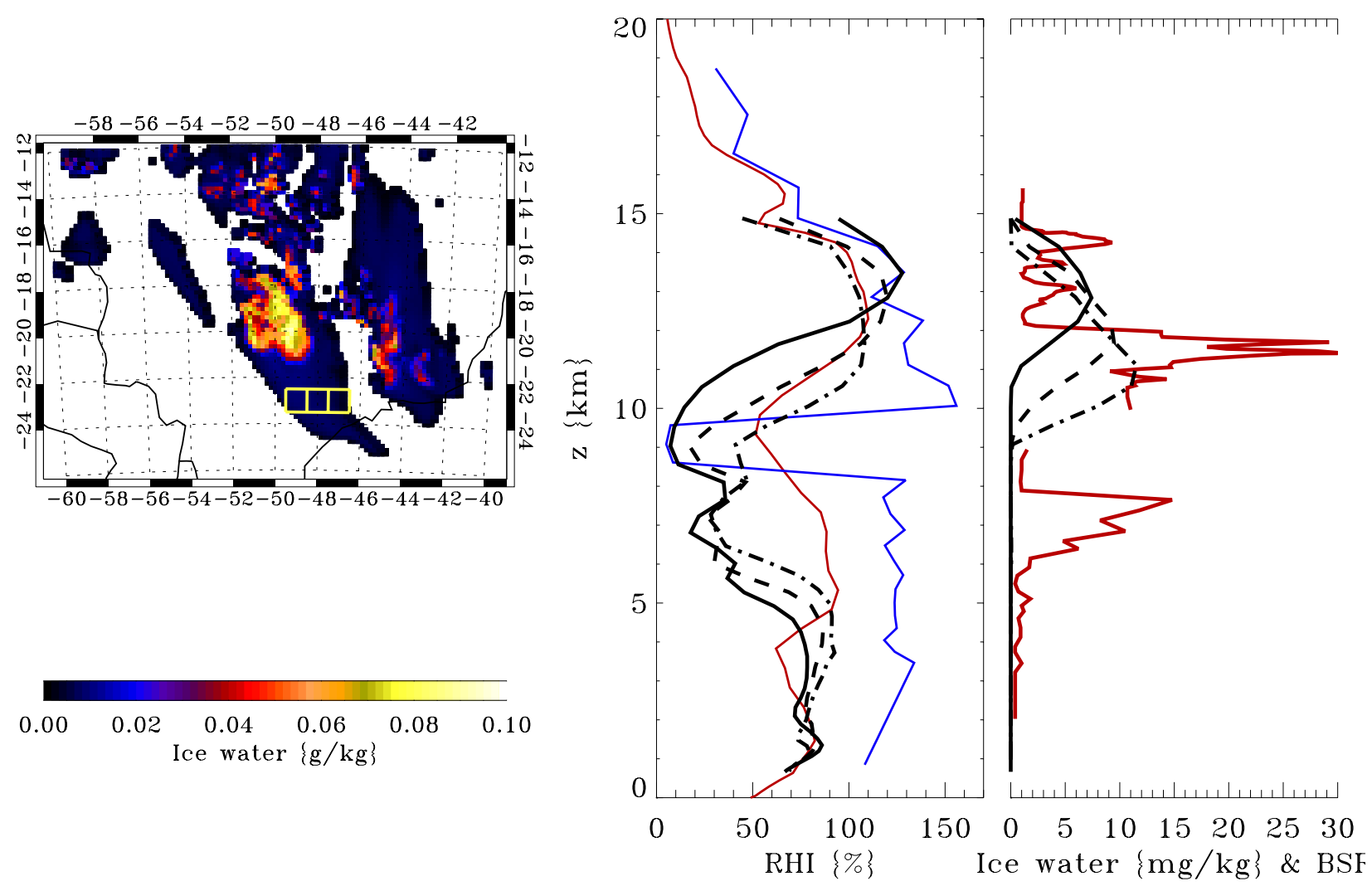

Fig. 6. Left: Ice water content from BOLAM at $12 \mathrm{~km}$ height on 24 January 23:00 UTC. Middle: Ice relative humidity from BOLAM averaged at (49 W, $23 \mathrm{~S}$ ) (black), at (48 W, $23 \mathrm{~S}$ ) (black dashed), and at (47 W, $23 \mathrm{~S}$ ) (black dot-dashed), BRAMS (red) and Micro-SDLA, interpolated on the BOLAM vertical resolution (blue). Right: BOLAM ice water and Micro-lidar backscatter ratio (red).

values reach $110 \%$ and exceed $130 \%$ in several grid points from individual profiles and that the microphysical scheme allows higher supersaturation values during the ice formation since the equilibrium requires several model timesteps to be reached. Figure 6 also shows the BRAMS (Brazilian Regional Atmospheric Modeling System Marécal et al., 2007) RHI for the SF4 flight interpolated at $48.5^{\circ} \mathrm{W}$ that can be compared with the corresponding BOLAM profile (dashed line, middle panel in Fig. 6). BRAMS and BOLAM vertical resolutions are comparable. The agreement is satisfactory with both models reproducing the supersaturated layer between 10 and $15 \mathrm{~km}$ height and giving the same RHI values. As mentioned above, the differences in the water vapour profile inside the outflow between the BRAMS and the BOLAM models can be attributed to the variability of the observed and modelled outflow in the SF4 measurement area. It is also interesting to briefly discuss the stratospheric intrusion at $9 \mathrm{~km}$ height. On one hand BOLAM shows extremely low water vapour contents leading to low RHI values (down to $10 \%$ ) in good agreement with Micro-SDLA. On the other hand BOLAM simulates a twofold and thicker intrusion, extending down to $5 \mathrm{~km}$ altitude. BRAMS reproduces the intrusion at the correct height but overestimates its water vapour content. Below the intrusion, RHI from BOLAM agrees with BRAMS and both models are drier than Micro-SDLA measurements.

\subsection{Trajectories}

Since the location, the temperature and the humidity conditions experienced by air parcels are key parameters for cirrus formation, Lagrangian trajectories on the global and regional scale based on meteorological analysis have been used in the literature to analyse the water vapour transport and the freezing in the TTL (e.g. Fueglistaler et al., 2005) and to identify the different types of tropical cirrus (Pfister et al., 2001). Clusters of backtrajectories are used here to identify the mechanisms leading to the formation of the observed cirrus during the SF4 flight. Trajectories are calculated from BOLAM using the on-line approach proposed by Gheusi and Stein (2002). The air parcel position is advected as a passive tracer. In addition to the 3-D transport with explicitly resolved winds, the location fields are also modified by the parametrized diffusion and the convective transport using a mass-flux method to re-adjust the vertical position inside the convective cloud. Despite the uncertainties related to this 

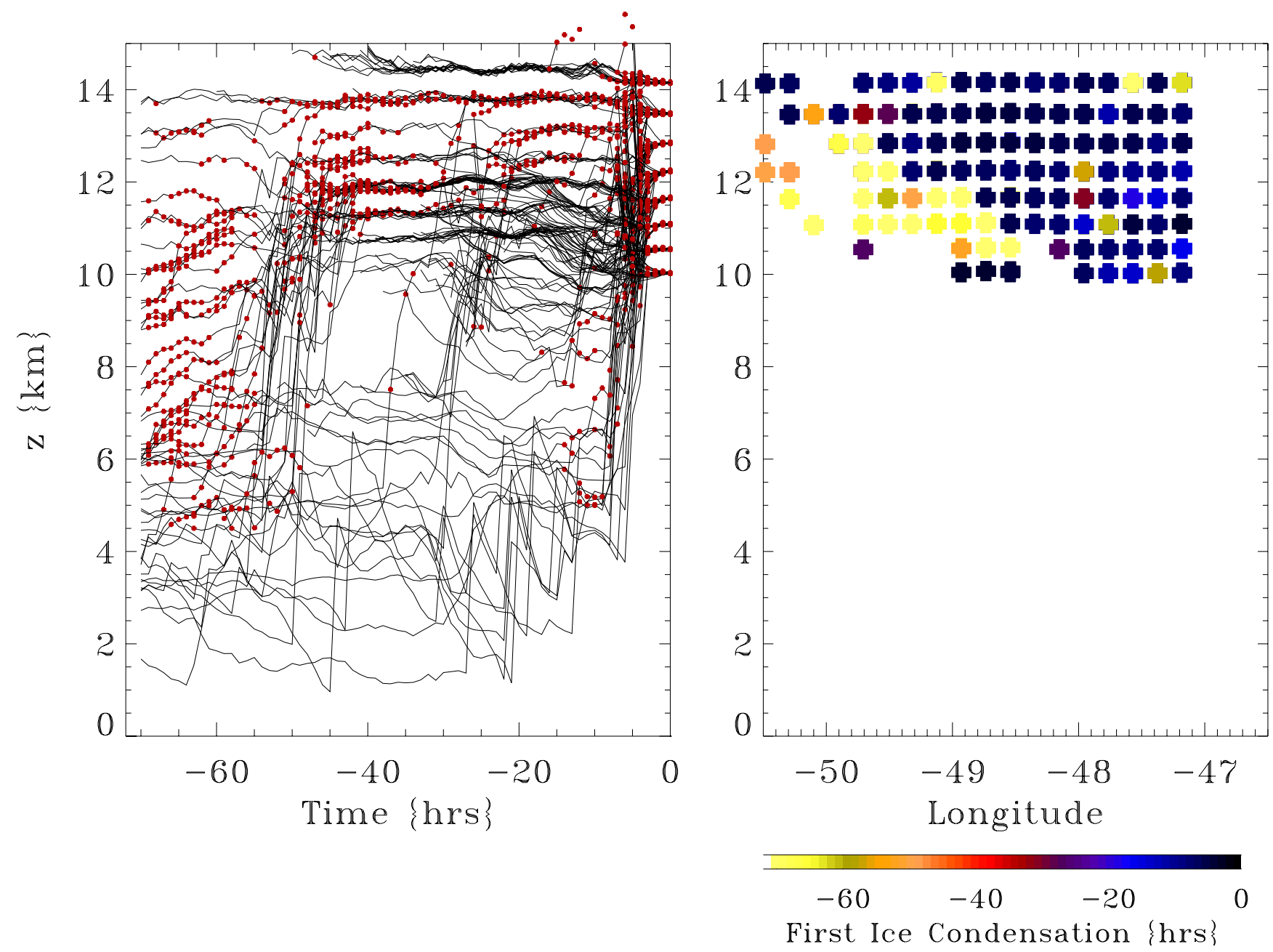

Fig. 7. Left: Cirrus airmass backtrajectory time evolution as a function of height. Small dots indicate the time and height where the ice saturation condition is satisfied for the first time. Right: Time $t_{c}$ inferred from the trajectories. $t_{c}$ is defined for each parcel as the earliset time when ice water forms.

approach, Gheusi and Stein (2002) have demonstrated that the lagrangian evolution can be studied on a qualitative basis for relatively large trajectory clusters. In the present paper, this method was used off-line and a time interval of $3 \mathrm{~h}$ is used to calculate the trajectories. The trajectories are calculated backward in time from 23:00 UTC, 24 February. They originate from the model grid points included in the region identified by the yellow boxes in Fig. 6 and range between 8 and $16 \mathrm{~km}$ height leading to about 3000 parcels. The water vapour, temperature, pressure and ice water fields are interpolated from BOLAM outputs at each trajectory point. The left panel in Fig. 7 shows the altitude of the trajectories ending inside the BOLAM cirrus layer as a function of time together with the time (height) when (where) the ice saturation condition is satisfied along the trajectories. A large fraction of the air masses is subject to a rapid uplift confirming that the main formation mechanism of the cirrus layers is the hy- dration due to convective outflows. Three distinct periods of uplift can be identified 60,30 and $6 \mathrm{~h}$ before the balloon measurements. They are well correlated with the maximum of convective activity shown in Fig. 5. The formation of ice occurs during the uplift and the ice phase water persists for the following $30 \mathrm{~h}$ in the airmasses that experienced the oldest convective ascents. It should be noted that the airmass at $13.8 \mathrm{~km}$ height shows the presence of cirrus for the whole set of trajectories. A few hours before the observation time, ice clouds form in air parcels experiencing the most recent uplift. The water vapour content along the trajectories (not shown) is higher for the parcels having experienced a recent uplift. The parcels processed by convection $60 \mathrm{~h}$ before the observation are firstly dehydrated in the upper troposphere and then re-hydrated during the last $10 \mathrm{~h}$ presumably by mixing with moist air coming from the recent outflow. Ren et al. (2007) shown that the inclusion of the rehydration in a Lagrangian 


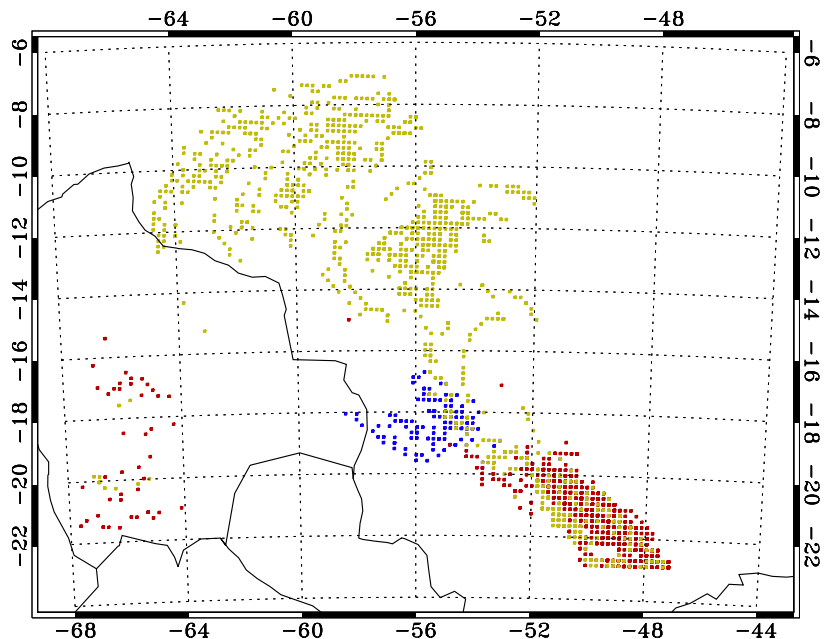

Fig. 8. Position of air parcels at time $t_{c}$ for cluster (a) (yellow dots) and cluster (b) (red dots). Blue dots indicate the position of air parcels at 13:30 UTC, 24 Febraury. See the text for the definition of clusters and the identification of the air parcels.

cirrus model provides more realistic results compared to insitu observations. The question arises of whether different uplift times and the presence of ice water can be correlated to the observed optical differences in the cirrus layers. In order to establish such a link the ice formation age $\left(t_{c}\right)$ is estimated for each observation point; $t_{c}$ is defined for each parcel as the earliest time when ice water forms. The plot of $t_{c}$ as a function of height and longitude is displayed in the right panel in Fig. 7. Most of the layer is composed of ice formed in the recent outflow $\left(t_{c}<20 \mathrm{~h}\right)$ and older uplift $\left(t_{c}>45 \mathrm{~h}\right)$ is found in the lower and western part of the layer. This means that the composition of the cirrus layer is determined by two different types of airmasses. This implies that the BOLAM cirrus at different longitudes (shown in Fig. 6, middle panel) form under different thermal and humidity conditions although they show similar ice water concentrations. In order to check the consistency of the thermal histories, trajectories are grouped in two clusters: (a) includes air parcels with $t_{c}>45 \mathrm{~h}$ and cluster (b) $t_{c}<20 \mathrm{~h}$. Figure 8 shows the geographical location of $t_{c}$ for cluster (a) (yellow points) and (b) (red points). Inside cluster (a) the ice forms in a vast region north of $13^{\circ} \mathrm{S}$ and in a well defined region centered around $53^{\circ} \mathrm{W}, 12^{\circ} \mathrm{S}$. This is roughly consistent with the scattered convection structure observed on 22 February and the organized system observed on 23 February at 03:00 UTC shown in Fig. 1. The parcels composing cluster (a) are then advected in the upper troposphere on the south western part of the convective region located north of Bauru. The ice clouds within cluster (b) form predominantly in the vicinity of the observation region during the convective uplifts on February 24. The trajectory analysis gives additional evidence of the large outflow variability with a transition between different $t_{c}$ during the SF4 flight. This evidence is certainly qualitative, since the model uncertainty in positioning the convective outflow could affect the longitude where such transitions occur in Fig. 7 but is consistent with the observations. Blue points in Fig. 8 shows the position of the parcels composing cluster (b) on 23 February at 13:50 UTC simultaneous to the MODIS observations shown in Fig. 2 top panels. The satellite data confirm that cluster (b) lies in a region where cirrus are observed. The BOLAM trajectory analysis strengthens the picture of hydrated air coming from recent outflows and also shows a region with older convective age related to an identified transport from a large scale structure of convection. Moreover the two layers are characterized by a different time of occurrence of cloud ice and a different water vapour content along the trajectories.

Therefore the BOLAM simulation provides the elements to interpret the humidity and aerosol observations: the cirrus in the lowest layers ( 2 and 3 in Fig. 3) are composed by a larger number of crystals, as shown by higher BSR values, and can be linked to the airmasses with lower $t_{c}$. A recent crystal formation could also explain the higher RHI measured by Micro-SDLA and the larger variability of aerosol backscatter ratio and humidity as seen in the observed vertical profile (Fig. 4). The higher cirrus layer (1) which is characterized by lower BSR and lower RHI values forms up to $60 \mathrm{~h}$ before the SF4. Despite the uncertainties due to the parametrized model microphysics the presence of ice water along the trajectories indicates that prolonged particle growth could form different types of crystals leading to lower BSR values, higher $D$ and reduced RHI. Mixing processes between older and recent outflows should also be considered. BOLAM trajectories indicate that clusters (a) and (b) end in adjacent regions. Finally it should be mentioned that the height of the aged convection outflow could be underestimated by the BOLAM model. The comparison with the GOES data reveals that during the first part of the simulation BOLAM underestimates the cloud top temperature and the extent of convection. This implies that in reality the older outflow is injected at higher altitudes in the troposphere than the picture given in Fig. 7. This would lead to a reversed cirrus layering with cluster (a) above cluster (b). Under this assumption, the trajectories would fully explain the observed cirrus layering. The role of gravity waves detected in the BSR data cannot be proven. It is possible to assume that the waves superpose to the main formation process which is convective hydration leading to a modulation of the efficiency of ice freezing and to a more rapid formation of small ice particles as shown by high BSR values in the core of the lowest layer.

\section{Conclusions}

The lidar observations from the flight SF4 performed during the Hibiscus campaign provide the evidence of two distinct cloud types based on their optical properties. The first class 
is characterized by higher values of BSR and lower values of $D$ while, for the second class, BSR has lower values and D higher values. The two types of clouds are observed at adjacent locations and at close altitudes. From the $D$ and BSR classification both clouds seem to fit the HACII typology proposed by Pfister et al. (2001) that is formed from recent and more aged (a few days old) convective outflows. The lidar data analysis suggests that the two types of cirrus clouds could be further distinguished in terms of particle size and shape, reflecting different formation mechanisms and thermal histories. This is confirmed by simultaneous humidity observations that reveal a different water content for the different cirrus typologies. The satellite data analysis and the modelling of transport confirm the convective origin of the two types of cirrus clouds. The SF4 flight was influenced by deep convection developing in a vast region north of Bauru during the days preceeding the flight leading to the uplift of moist air in the upper troposphere at different times. The mesoscale model simulation agrees well with the observations of cirrus in supersaturated air above $11.5 \mathrm{~km}$ height and with the simulations carried out with an independent model. Moreover, the mesoscale simulations provide a robust interpretation of the observed differences based on the different convective uplift times and water contents experienced along the trajectories. Despite the highly parametrized microphysics the mesoscale simulation reveals that the formation processes for the observed cirrus clouds are mainly related to the convection and associated transport that are generally well reproduced. This analysis that follows previous observational studies confirms that the cirrus clouds can have a complex structure related to concurrent formation processes. It should be stressed that the different particle concentrations and dimensions, as inferred from the lidar data, can be related to the thermodynamic conditions experienced by the airmasses. This can have an impact on model estimates of the radiative and water vapour budgets in the upper troposphere which are crucial in the study of the upper troposphere and lower stratosphere climate systems and their feedbacks. The approach presented here for a single case study, that has provided a detailed analysis and an assessment of the parametrized model processes, could be extended in a statistical sense at the regional or global scales using satellite based and in-situ regular observations of cirrus.

Acknowledgements. This study was supported by the EU through the Hibiscus project of the VIFP. Maurizio Viterbini and Carlo Buontempo are acknowledged for their support in the field campaign. The ECMWF is acknowledged for providing the atmospheric analysis used in this work. Finally, the authors wish to thank Dominik Brunner for providing the GOES data.

Edited by: R. MacKenzie

\section{References}

Ackerman, T. P., Liou, K.-N., Valero P. J., and Pfister L.: Heating rates in tropical anvils, J. Atmos. Sci., 45, 1606-1623, 1988.

Buzzi, A. and Foschini, L.: Mesoscale meteorological features associated with heavy precipitation in the southern Alpine region, Meteorol. Atmos. Phys., 72, 131-146, 2000.

Corti T., Luo, B. P., Fu, Q., Vomel, H., and Peter, T.: The impact of cirrus clouds on tropical troposphere-to-stratosphere transport, Atmos. Chem. Phys., 6, 2539-2547, 2006, http://www.atmos-chem-phys.net/6/2539/2006/.

Davies H. C.: A lateral boundary formulation for multilevel prediction models, Q. J. R. Meteorol. Soc., 102, 405-418, 1976.

Dessler, A. E. and Yang, P.: The Distribution of Tropical Thin Cirrus Clouds Inferred from Terra MODIS Data, J. Climate, 16, 1241-1247,2003.

Di Donfrancesco, G., Cairo, F., Buontempo, C., et al. : Balloonborne Lidar for cloud physics studies, Appl. Opt., 42, 22, 57015708, 2006.

Durry, G., Huret, N., Hauchecorne, A., Marecal, V., Pommereau, J.-P., Jones, R. L., Held, G., Larsen, N., and Renard, J.-B.: Isentropic advection and convective lifting of water vapor in the UT - LS as observed over Brazil $\left(22^{\circ} \mathrm{S}\right)$ in February 2004 by in situ high-resolution measurements of $\mathrm{H} 2 \mathrm{O}, \mathrm{CH} 4, \mathrm{O} 3$ and temperature, Atmos. Chem. Phys. Discuss., 6, 12469-12501, 2006, http://www.atmos-chem-phys-discuss.net/6/12469/2006/.

Folkins, I. and Martin, R.V.: The vertical structure of tropical convection and its impact on the budgets of water vapor and ozone, J. Atmos. Sci.,62, 1560-1573, 2005.

Fueglistaler, S., Bonazzola, M., Haynes, P. H., Peter, T.: Stratospheric water vapor predicted from the Lagrangian temperature history of air entering the stratosphere in the tropics, J. Geophys. Res., 110, D08107, doi:10.1029/2004JD005516, 2005.

Fueglistaler, S. and Fu, Q.: Impact of clouds on radiative heating rates in the tropical lower stratosphere, J. Geophys. Res., 111, D23202, doi:10.1029/2006JD007273, 2006.

Gettelman, A., Salby, M. L., and Sassi, F.: Distribution and influence of convection in the tropical tropopause region, J. Geophys. Res.-Atmos.,1737-1746, doi:1029/2006JD004080, 2002.

Gheusi, F. and Stein, J.: Lagrangian description of airflows using Eulerian passive tracers, Q. J. R. M. S., 128, 579, 337-360, 2002.

Hartmann, R. L.: Radiative effects of clouds on Earth's climate. Aerosol-Cloud-Climate Interactions,International Geophysical Series, 54, Academic Press, P. V. Hobbs Editor, 151-173, 1993.

Holton, J. R., Haynes, P. H. , Douglass, A. R., Rood ,R. B., and Pfister, L.: Stratosphere-troposphere exchange. Rev. Geophys., 33(4),403-439, 1995.

Kain, J. S. and Fritsch, J. M.: A one-dimensional entraining/detraining plume model and its application in convective parameterization. J. Atmos. Sci., 47, 2784-2802, 1990.

Kain, J. S. and Fritsch, J. M.: Multiscale Convective Overturning in Mesoscale Convective Systems: Reconciling Observations, Simulations, and Theory, Mon. Wea. Rev., 126, 2254-2273, 1998.

Kain J. S.: The Kain-Fritsch convective parametrization: an update, J. App. Meteorol., 43, 170-181, 2004.

King, M. A., Chee, S., Platinick, S. E., Wang, M., and Liou, K.: Cloud Retrieval Algorithms for MODIS: Optical Thickness, Effective Particle Radius, and Thermodynamic Phase, Algorithm Theoretical Basis Document No. ATBD-MOD-MOD06 Cloud product, 1997. 
Lehman, R.: On the choice of relaxation coefficients for Davies' lateral boundaries scheme for regional weather prediction models, Meteorol. Atmos. Phys., 52, 1-14, 1993.

Liou, K.-N.: Influence of cirrus clouds on weather and climate processes: A global perspective, 1986, Mon. Wea. Rev., 114, 11671200, 1986.

Liu, L. and Mishchenko, M. I.: Constraints on PSC particle microphysics derived from lidarobservations, Journal of Quantitative Spectroscopy and Radiative Transfer, 70, 817-831, 2001.

Liu, C. and Zipser, E. J.: Global distribution of convection penetrating the tropical tropopause, J. Geophys. Res., 110, D23104, doi:10.1029/2005JD006063, 2005.

Mace, G. G., Zhang, Y., Platnick, S., King, M. D., Minnis, P., and Yang, P.: Evaluation of Cirrus Cloud Properties Derived from MODIS Data Using Cloud Properties Derived from GroundBased Observations Collected at the ARM SGP Site, J. Appl. Meteorol., 44, 221-240, 2005.

Mace, G. G., Benson, S., and Vernon, E.: Cirrus Clouds and the Large-Scale Atmospheric State: Relationships Revealed by Six Years of Ground-Based Data, J. Climate, 19, 3257-3278, doi:10.1175/JCLI3786.1, 2006.

Marécal V., Durry G., Longo K., Freitas S., Riviere E.D. and M. Pirre: Mesoscale modelling of water vapour in the tropical UTLS: two case studies from the HIBISCUS campaign, Atmos. Chem. Phys., 7, 1471-1489, 2007,

http://www.atmos-chem-phys.net/7/1471/2007/.

Marti, L. and Mauersberger, K.:A survey and new measurements of ice vapor pressure at temperatures between 170 and $250 \mathrm{~K}$, Geophys. Res. Lett., 20, 363-366, 1993.

Massie, S., Gettelman, A., Randel, W., and Baumgardner, D.: Distribution of tropical cirrus in relation to convection, J. Geophys. Res., 107(D21), 4591, doi:10.1029/2001JD001293, 2002.

McFarquhar, G. M. and Heymsfield, A. J.: Microphysical characteristics of three anvils sampled during the Central Equatorial Pacific Experiment, J. Atmos. Sci.,53, 2401-2423, 1996.

Morcrette, J. J., Clough, S. A., Mlawer, E. J., and Iacono, M. J.: Impact of a validated radiative transfer scheme, RRTM, on the ECMWF model climate and 10-day forecasts. ECMWF Technical Memo., 252, 1998.

Noel, V., Winker, D. M., McGill, M., and Lawson P.:Classification of particle shapes from lidar depolarization ratio in convective ice clouds compared to in situ observations during CRYSTAL-FACE, J. Geophys. Res., 109, D24213, doi:10.1029/2004JD004883, 2004.

Pfister, L., Selkirk, H. B., Jensen, E. J., et al.: Aircraft observations of thin cirrus clouds near the tropical tropopause, J. Geophys. Res., 106(D9), 9765-9786, 2001.

Pommereau, J.-P., Garnier, A., Held, G., Gomes, A.-M., Goutail, F., Durry, G., Borchi, F., Hauchecorne, A., Montoux, N., Cocquerez, P., Letrenne, G., Vial, F., Hertzog, A., Legras, B., Pisso, I., Pyle, J. A., Harris, N. R. P., Jones, R. L., Robinson, A., Hansford, G., Eden, L., Gardiner, T., Swann, N., Knudsen, B., Larsen,
N., Nielsen, J., Christensen, T., Cairo, F., Pirre, M., Marcal, V., Huret, N., Rivire, E., Coe, H., Grosvenor, D., Edvarsen, K., Di Donfrancesco, G., Ricaud, P., Berthelier, J.-J., Godefroy, M., Seran, E., Longo, K., and Freitas, S.: An overview of the HIBISCUS campaign, Atmos. Chem. Phys. Discuss., 7, 2389-2475, 2007, http://www.atmos-chem-phys-discuss.net/7/2389/2007/.

Pressman, D. J.: Chislennaja model' gidrotermicheskikh processov v pochve kak chast' skhemy mezomasshtabnogo prognoza (A numerical model of hydrothermical processes in soil as a part of a mesoscale weather forecast scheme), Meteorologiya i gidrologiya (Meteorology and Hydrology), 11, 62-75, 1994 (in Russian).

Ren, C., MacKenzie, A. R., Schiller, C., Shur, G., and Yushkov, V.: Diagnosis of processes controlling water vapour in the tropical tropopause layer by a Lagrangian cirrus model, Atmos. Chem. Phys., 7, 5401-5413, 2007, http://www.atmos-chem-phys.net/7/5401/2007/.

Ritter, B. and Geleyn, J.: A comprehensive radiation scheme for numerical weather prediction models with potential applications in climate simulations, Mon. Wea. Rev., 120, 303-325, 1992.

Sassen, K. and Benson, S.: A Midlatitude Cirrus Cloud Climatology from the Facility for Atmospheric Remote Sensing. Part II: Microphysical Properties Derived from Lidar Depolarization, Journal of Atmospheric Sciences, 58, 2103-2112, 2001.

Saunders, R. and Brunel, P.: RTTOV 8.5 user guide, EUMETSAT SAFNWP http://www.metoffice.gv.uk/research/interproj/ nwpsaf/rtm/, 2004.

Schultz, P.: An explicit cloud physics parameterization for operational numerical weather prediction, Mon. Wea. Rev, 123, 33313343, 1995.

Shibata T., Voemel H., Hamdi S., Kaloka S., Hasebe F., Fujiwara M., and Shiotani M.: Tropical cirrus near cold point tropopause under ice supersaturated condition observed by lidar and balloonborne cryogenic frost point hygrometer, J. Geophys. Res., 112, D03210, doi:10.1029/2006JD007631, 2007.

Tompkins A. M., Gierens, K., and Radel G.: Ice Supersaturation in the ECMWF Integrated Forecast System, ECMWF technical memorandum, 481, 2005.

Wang, P. H., Minnis, P., McCormick, M. P., Kent, G. S., and Skeens, K. M.: A 6-year climatology of cloud occurence frequency from Stratospheric Aerosol and Gas Experiment II observations (1985-1990), J. Geophys. Res., 101, 29 407-29429, 1996.

Whiteway, J., Cook, C., Gallagher, M., et al.: Anatomy of cirrus clouds: Results from the Emerald airborne campaigns, Geophys. Res. Lett., 31, L24102, doi:10.1029/2004GL021201, 2004.

Zampieri, M., Buzzi A., and Malguzzi, P.: Sensitivity of quantitative precipitation forecasts to boundary layer parameterization: a flash flood case study in the Western Mediterranean, Nat. Hazards Earth Syst. Sci., 5, 603-612, 2005, http://www.nat-hazards-earth-syst-sci.net/5/603/2005/. 